\title{
Assessment and measurement of energy demand and efficiency in public lighting networks
}

\author{
D. Gasparovsky ${ }^{1}$, P. Schwarcz ${ }^{2} \&$ P. Janiga ${ }^{1}$ \\ ${ }^{1}$ Slovak University of Technology, Slovak Republic \\ ${ }^{2}$ Tungsram-Schréder Zrt., Hungary
}

\begin{abstract}
Due to technological developments in the last decades and to a long lifetime of installations, public lighting is recognized as one of the fields in lighting with significantly high energy saving potential. Side by side there exist obsolete systems older than 40 years and new modern high-performance systems with discharge lamps and powerful luminaire optics as well as promising LED technologies and sophisticated lighting control systems. To promote energy efficient solutions and to support or speed-up re-constructions of old systems, it is desirable to create tools for decision makers and municipal authorities helping them to distinguish between good and better. Linking thoughts to other lighting fields like EPBD, a numerical indicator expressing the energy efficiency level is to be set up. Works on this task currently run in CEN as a European normalization body as well as world widely recognized CIE.

This paper focuses on analysis of different approaches that are actually discussed. A leading role is played by SLEEC (Lighting Energy Efficiency Criterion), a working name for a new lighting energy indicator proposed for public lighting systems. It is based on effective system comprising of the effective power of lamps, gears and other devices like control units, directly associated to the lighting of the area to be lit. Switching profiles, lighting control and operator's behavior or preferences should be considered as well. Depending on the main user and respective lighting class, different versions of SLEEC are proposed. The paper attempts to generalize the leading approach, branching into different variants and discussing their pros and cons. Methods and schemes for measurement of SLEEC are also proposed.
\end{abstract}

Keywords: energy efficiency, public lighting, road lighting, SLEEC. 


\section{Introduction}

The importance of energy efficiency is increasing rapidly. The European Commission has already adopted two eco-design regulations to improve the energy efficiency of household lamps, office, street and industrial lighting products. The two regulations lay down energy efficiency requirements which will save close to $80 \mathrm{TWh}$ by 2020 (roughly the electricity consumption of Belgium) and will lead to a reduction of about 32 million tons of $\mathrm{CO}_{2}$ emissions per year. It is known that the implemented measures alone are not enough the reach ambitious targets of EU by 2020. Energy savings potential on system levels are at least as high as on product level. That is why the Commission's focus is on improved measures on products, energy labeling and introducing the Lighting System Legislation (LSL). LSL is an energy conscious way of design, installation and operation of lighting systems:

1. selection of the right criteria for the lighting task

2. design of the right lighting to meet lighting and energy saving criteria

3. verification of the lighting design

4. installation of the lighting system according to the lighting design

5. verification of lighting quality and energy saving criteria of the new installation by metering

6. commissioning, sign-off and hand over to the user of the lighting installation

7. maintenance, service (schedule defined the design) and operation of the installation by the user

8. verification of lighting quality and energy saving criteria of the maintained installation by metering.

The process above for office lighting is backed with a series of directives and standards. In contradiction, highlighted steps for street lighting are not covered by accepted EU standards [1] and verified practice of calculation and measurement. Highlights here do not indicate priorities, just a sign for the lack of legislation.

Those energy saving elements were targeted by the statement from CIE (International Commission on Illumination) during the Session in Beijing 2007, which led to formation of Technical committees. Current works in CEN (European Committee for Standardization) aim to develop a system for assessment of energy efficiency of street lighting systems as a possible framework for energy labeling of these systems. Those missing elements are subjects of the present paper. CIE publications [2] are essential for preparation of EU standards and for lighting practice.

Energy savings in public lighting are studied in many European countries. Comprehensive studies have been performed e.g. in Slovakia and the Czech Republic [3]. As continuously emphasized in CIE, energy savings must not decrease the lighting quality and proper lighting [4] has to remain the framework objective. 


\section{Derivation of the Street Lighting Energy Efficiency Criterion (SLEEC)}

For expression of energy efficiency level of public lighting (street lighting) systems, a work name Lighting Energy Efficiency Criterion (abbreviated as SLEEC) is introduced. However, definition of this criterion (in fact an indicator) is still a subject of vivid discussions. Up to now, several less or more compatible approaches are available. Leading approach can be defined by generalization of various particular formulae for calculation of SLEEC, having common philosophy. Some other approaches are briefly discussed in Section 3. General formula for calculation of SLEEC can be composed as follows:

$$
\text { SLEEC }=\frac{\text { Power Demand }}{(\text { Luminous Parameter }) \mathrm{x}(\text { Relevant Area })}
$$

\subsection{Power demand of a lighting installation}

Different approaches may lead to usage of one of the following:

$\mathrm{A} /$ Installed Power $\mathrm{P}(\mathrm{kW})$ : Total input power of all installed luminaires (including lamps, ballasts and control gears) and other energy consuming devices (e.g. for control or monitoring purposes) installed in electrical compartments (poles, switchboards) within the defined relevant area. Installed power approach is easier for calculation but does not take into account lighting control and its benefits to energy demand of the lighting system. For the sake of simplicity, losses in cables can be neglected in the design stage.

B/ Annual Power Consumption W (kWh): Suitable switching profiles [5], light dimming [6] and other techniques may contribute to optimize energy utilization for public lighting. Due to seasonal changes of daylight availability, at least one-year basis should be used for setting up the parameter. If no dimming is applied, standard annual operation times can be derived for different geographical locations. However, particular local conditions or requirements may be applied as well. If dimming systems are to be installed, lighting levels should correspond to lighting classes linked to the relevant area as per EN 13201-2 [1] or CIE 115 [2], differentiated for normal (full-level) and dimmed operational regimes. Lighting designer has to consider all assumptions and calculations perform with the most probable switching/control diagram (for examples see Fig. 1). The diagram must be attached to calculations as part of the lighting project.

Power consumption approach is more complex than installed power approach though shortcomings can be seen in the ambiguity of results as a consequence of different switching/control profiles used for calculations, depending on particular lighting system. On the other hand, annual consumption principle is used also in other schemes, as such as LENI for assessment of energy performance of lighting in buildings [7]. 


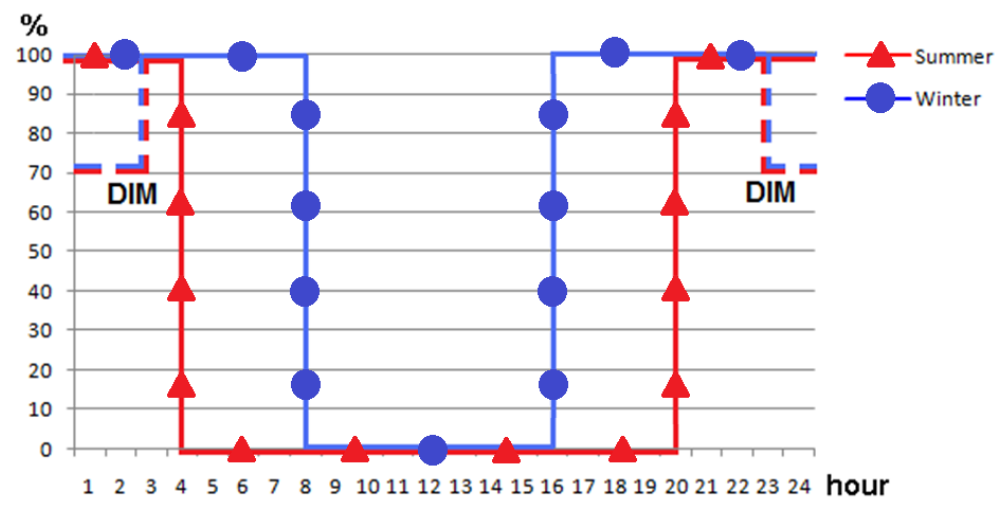

Figure 1: Typical daily switching profile for $50^{\circ}$ latitude with and without light dimming.

Installed power can be calculated using the formula as follows:

$$
P=\sum_{i=1}^{N}\left(n_{i} x P_{L i}\right)+P_{C i}
$$

where

$\mathrm{P}_{\mathrm{Li}} \quad$ - rated input power of a particular luminaire type

$\mathrm{n}_{\mathrm{i}} \quad$ - number of installed luminaires of a particular type within the area

$\mathrm{i}, \mathrm{N} \quad$ - index and number of different luminaire types

$\mathrm{P}_{\mathrm{Ci}}$ - total input power of all lighting control installed outside of luminaires, exclusively concerning the relevant area

In general, annual power consumption can be expressed as follows:

$$
W=\int_{\text {year }} P \cdot d t
$$

Assuming that in public lighting only limited number of lighting levels is applied, following simplification of the formula (3) can be introduced:

$$
W=\sum_{i=1}^{365} \sum_{j=1}^{M}\left(P_{i j} x t_{i j}\right)
$$

where

$\mathrm{t}_{\mathrm{ij}} \quad$ - daily operation time of a particular lighting level

$\mathrm{P}_{\mathrm{ij}} \quad$ - installed power expressed by formula (2) reduced according to corresponding lighting level (NB: reduction of luminous flux generally do not gain in linear decrease of power)

j, M - index and number of different pre-set lighting levels

If different light levels are applied, segregation of formula (1) to individual levels is needed. More detailed calculations are needed in these cases:

- $\quad$ if more complex profiles are used to control the lighting

- $\quad$ if adaptive lighting systems are used (only estimations can be performed)

- if individual luminaire control is used 


\subsection{Luminous parameter}

Luminous parameter is used to relate the energy demand to lighting level of the illuminated relevant area $[8,9]$. More illumination calls for higher consumption, so the mutual ratio of the two parameters help to describe efficacy of lighting systems similarly like luminous efficacy of lamps is defined, though here in reciprocal expression. Luminous parameter is strongly dependant on lighting class of the relevant area. Design criterion is either based upon luminance $\mathrm{L}\left(\mathrm{cd} \cdot \mathrm{m}^{-2}\right)$ [10] or illuminance E (lx) what necessarily leads to split of formulae to L- and E-based SLEEC. Besides the said, following approaches can be identified:

A/ Normative parameter: If normative parameter is used, result of calculation will point to overall energy efficiency of analyzed lighting system, when common basis is used to compare different lighting systems under standard conditions. Such assessment can show the quality of designer's effort to fulfill the desired lighting levels with least power demand. Big difference between normative and calculated values of a luminous parameter will lead to worse ranks of the lighting system.

B/ Calculated parameter: In contradiction to the previous approach it may be desired (e.g. by municipalities) to have higher lighting levels than required by standards, e.g. for marketing purposes. Technical standards (EN 13201-2 for instance) require only minimum levels, while range from the upper side is open, in fact. Therefore, if the calculated parameter is used for assessment, the result of the calculation will emphasize energy efficiency of technologies incorporated (lamps, luminaires, accessories), regardless on dimensioning of the system.

\section{Identified problems:}

- In some cases, relevant area (e.g. straight road) is required not to be solely illuminated from edge to edge, some part of luminous flux should be used to illuminate the proximate surrounding (requirement set through the ,surround ratio" parameter).

- One lighting system quite usually serves to illuminate more than one area, for example road + sidewalks (sometimes separated by grass strips capturing light; such light losses exceeding required surround ratio level cannot be effectively controlled).

- In parks, lighting is not aimed only to illuminate footpaths but to help increase the feeling of safety and to create pleasant lighting atmosphere e.g. by illumination of trees from the bottom. This cannot be considered as unuseful spill light. Similar situation is on places where building facades have to be illuminated to some level.

\subsection{Relevant area $\mathbf{A}\left(\mathrm{m}^{2}\right)$}

Relevant area A $\left(\mathrm{m}^{2}\right)$ defines the density of lighting system efficacy (energy demand over luminous parameter). Two main typical situations can be distinguished: 
A/ Straight road: This situation (fig. 2) is typical for luminance based systems because application of the luminance concept requires at least a certain straight section of road (calculation area between two consequent poles plus $60 \mathrm{~m}$ braking distance before this area). This approach can be with no limitations used for the illuminance approach as well. Though in practice indicators relating installed power or power per lux or cd. $\mathrm{m}^{-2}$ to $1 \mathrm{~km}$ of a road are sometimes used, the true value of this parameter is only informative. As width of the illuminated road has significant meaning, it cannot be neglected and tabelization of values for different typical road widths seem to be impractical.

B/ Any closed area: This situation (fig. 3) can only be used for illuminance based systems. Transversal profile of roads or lighting system geometry is not critical for this approach. Closed area may include any number of installed luminaires, any number of distribution boxes and any topology of cable routes. Area to be taken into account should be carefully calculated, depending on the illumination task. For example, if in a park the task is only to illuminate footpaths, the total area is summed up from particular sections of these footpaths. If aim is to illuminate the park as a whole, total park area should be taken (intentional dark places should be excluded).

Relevant area for the case of a straight road can be calculated as follows:

where

$$
A=l x w
$$

1 - length of the relevant section of road

w - width of the road

Some roads are not ideally straight but small differences are negligible. For general case of quasi-straight roads with curvatures, bends and variable widths more detailed calculations are needed, using the following formula:

$$
A=\int_{\text {section }} l . d w
$$

If requirements to accuracy of calculations are not very high, the following simplified formula can be used instead of the previous two:

$$
A=n \times s
$$

where

$\mathrm{n} \quad$ - number of poles installed on the relevant road section

$\mathrm{s} \quad$ - typical spacing of poles in a linear (single side) geometry

\section{Analysis of efficiency of street lighting systems}

Assuming that lighting designer aims to reach required lighting levels with minimum power consumption, optimization of lighting design is needed. In general, results of lighting calculation should always be higher than minimum values prescribed by standards. Designer working with discrete inputs (power of lamps, selection of luminaires and optics, heights depending on available poles, 
spacing usually taken e.g. in $1 \mathrm{~m}$ steps) should seek for minimum difference between his result and normative requirement. The same time, spill of luminous flux to unnecessary area or directions should be limited as much as possible. Overall efficiency of lighting systems can be defined as the ratio of luminous flux necessary to fulfill the lighting function to the total luminous flux of all lamps installed within the relevant area.

Overall efficiency incorporates:

- Luminous efficacy of lamps: depends on lamp type and its power; some lamp types are available in standard and improved versions, the latter having increased luminous flux thus better luminous efficacy. Luminous efficacy of the light source is usually determined in nominal (optimal) circumstances, Nevertheless, light source at the luminaire works far from nominal. In that case, luminous efficacy in real situation will be different (usually smaller) than that for optimal. Typical example is the luminous efficacy of LEDs given at chip temperature of $25^{\circ} \mathrm{C}$ and nominal current, although chip temperature and actual current will be different in reality. This must be taken into account, when overall efficiency is calculated. For example of LEDs, 'thermal efficiency' can be calculated, which indicates the ratio of efficacy at nominal and real situations.

- Luminous efficiency of luminaires: given by quality of optics (e.g. highreflectance MIRO vs. cheap diffuse reflector) and construction of the luminaire (e.g. deep flat-glass vs. shallow luminaires).

- Maintenance factor: It is multiplied from lumen depreciation of the light source and the maintenance factor of the luminaire. Lumen depreciation is a function of the depreciation curve and designed replacement cycle of the source. The maintenance factor of the luminaire depends on quality of environment, prescription of maintenance, materials and tightness of luminaires.

- Efficiency of ballast: in case of magnetic ballasts, approximately $20 \%$ of luminaire's rated power is consumed by ballast while for electronic ballasts this portion can approach near towards 0 .

- Lighting control: A combination of all mentioned parameters result to certain $\mathrm{W} / \mathrm{L}$ or W/E values (see Eq. (1) above). Direct application of these parameters is an alternative approach how to express and calculate the SLEEC. Problems with this approach may occur, if different technologies are used in the relevant area.

Lighting systems ranking to the highest energy efficiency class should fulfill these criteria:

- Most efficient light sources for the purpose (usually high-pressure sodium lamps)

- Lamp versions with increased luminous flux (e.g. PLUS or SUPER denoted versions)

- Luminaire efficiency better than 0,75 
- Good luminous intensity distribution for the purpose (well-designed and optimized optics, selectable according to the application for some luminaire types)

- Maintenance factor not below 0,80

Note: Cleanliness of the environment has significant influence on energy consumption and efficiency of lighting system through the maintenance factor. Moreover it is an attribute that usually cannot be improved. Thus, ranking of lighting systems will always comprise this property of the installation site.

\section{Measurement of SLEEC in public lighting networks}

In order to verify calculated values of SLEEC, measurement is an alternative method. For new or renovated lighting systems, SLEEC can be calculated in the designing stage while measurement can support the first inspection of this system, possibly together with electrical tests of the lighting network and/or photometrical measurements.

It is necessary to distinguish between short-term and long-term measurements. Although for calculation method the energy consumption parameter is preferred (see Section 2), its verification requires continuous energy monitoring during minimum one year period what is time demanding. Other complication comes from the fact that it is almost impossible to permanently install measuring instruments in desired points of network or in every pole or luminaire. Sophisticated control systems may provide this option and "smart metering" seems to be a promising technique, this approach is, however, out of the scope of this paper.

For certification purposes, instantaneous measurements based on input power can be used. For a straight road and linear electrical line topology, the measurement scheme is depicted in Fig. 2. In certain points where the network is branched, electrical parameters like voltage, current and power are to be measured. Arrows in Fig. 2 show the flow of energy (from sources to appliances). Positive values of current or power (P, Q, S, PF) are given to all inputs while negative values are linked to outputs. Such a way, remaining difference represents the parameters of the relevant area.

Voltage shall be measured in each point as well because voltage drop along the line impacts the real input power of luminaires. As a consequence, input power will in real differ from rated power and will vary from luminaire to luminaire.

Measurements according to the scheme in Fig. 2 can be performed on terminal blocks installed in foots of poles if the network is looping through. In case of overhead lines, connections are also easily accessible. But if buried cables are not looping via terminal blocks in poles and buried T-connectors are used, the method described above is not usable. For this case there is no practical solution up to now but the problem is identified and solutions are sought. 


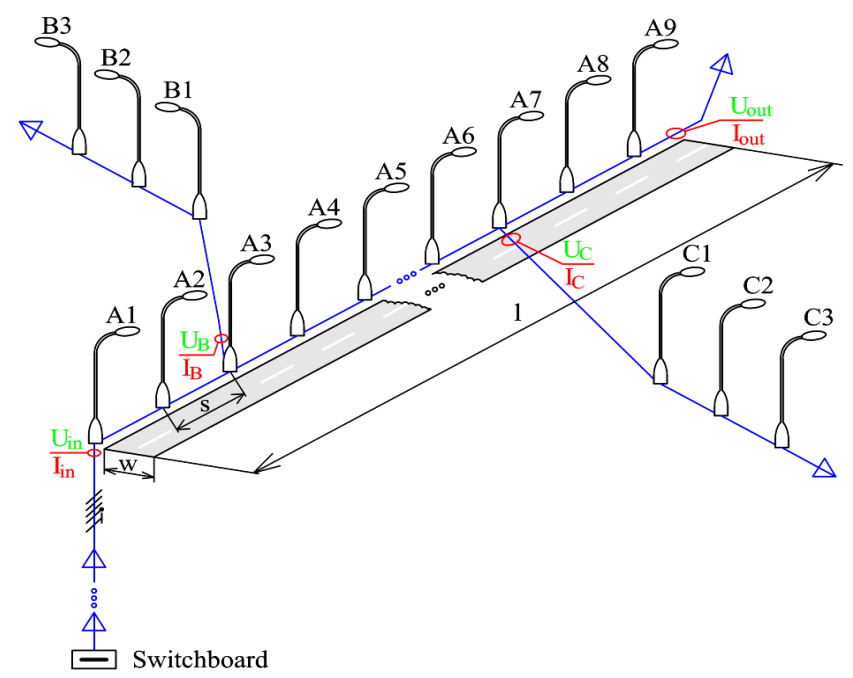

Figure 2: Example of measurement diagram with relevant area as a straight road.

If relevant area has an irregular shape, like in case of parks, places or pedestrian zones, measurements can be performed in a similar way as described above. Situation is depicted in Fig. 3. Here, inputting and outputting lines are

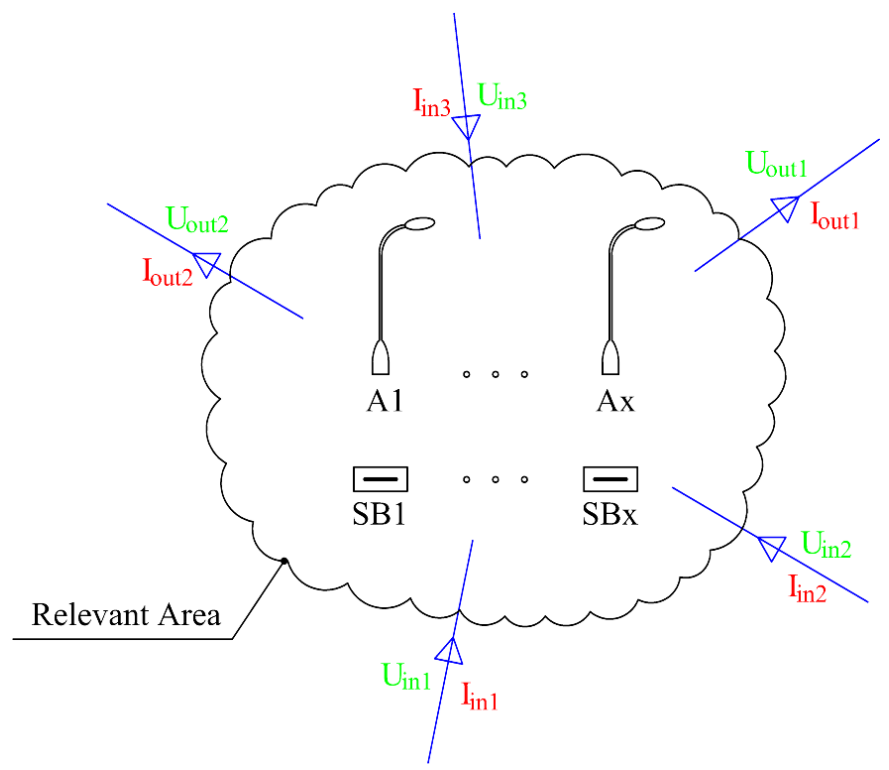

Figure 3: Example of measurement diagram with relevant area of an arbitrary shape. 
also measured in bordering points of the relevant area. Internal sources represented by switchboards SB1 to SBx need to be included as well. In that case measurements have to be performed also on output terminal blocks of these switchboards.

\section{Sample calculations and measurements of the SLEEC}

In-situ measurements of power quality have been performed in a real lighting network described below in Table 1. Comprehensive measurement of power quality was induced by overvoltage problems [11] arising from switching processes, investigation of harmonic distortion in public lighting networks [12] and related problems. Measurements have been performed in accordance with recommended practice $[13,14]$. Purpose of measurements was not primarily focused on SLEEC, but all necessary parameters for SLEEC have been recorded and measurements have been performed in accordance with requirements described in the previous section.

Lighting system is renovated and original lighting project with proper calculations is available. In comparison to measured values, SLEEC is also calculated by means of formulae given in Section 2 with these variations:

A: Power in W, normative L

B: Power in W, calculated/measured L

C: Consumption in kWh, normative/calculated L, 3900 hours/year (only by calculation)

D: Consumption in $\mathrm{kWh}$, normative/calculated L, 2075 hours/year on full level and 1825 hours/year on reduced 70\% level (only by calculation)

Table 1: $\quad$ Identification of the installation site.

\begin{tabular}{|l|l|}
\hline Locality $\left(48,1^{\circ} \mathrm{N} / 17,7^{\circ} \mathrm{E}\right)$ & Galanta \\
\hline Lamp type & NAV-T 100 W SUPER 4Y \\
\hline Lamp efficacy & $100,0 \mathrm{~lm} / \mathrm{W}$ \\
\hline Luminaire type & Schréder Sapphire 12N100PC \\
\hline Luminaire efficiency & 79 \\
\hline Luminaire's rated power & $121 \mathrm{~W}$ \\
\hline Mounting height & $8 \mathrm{~m}$ \\
\hline Average spacing of poles & $30 \mathrm{~m}$ \\
\hline Width of the road & $6 \mathrm{~m}$ \\
\hline Length of the relevant road section & $297 \mathrm{~m}$ \\
\hline Lighting class & ME4b \\
\hline $\begin{array}{l}\text { Normative/Calculated/Measured maintained } \\
\text { luminance }\end{array}$ & $0,75 \mathrm{~cd} \cdot \mathrm{m}^{-2}$ \\
\hline Maintenance factor & 0,73 \\
\hline Number of poles & 9 \\
\hline Total rated power of luminaires & $1089 \mathrm{~W}$ \\
\hline Measured installed power of the installation & $882 \mathrm{~W}$ \\
\hline
\end{tabular}


In the studied case, calculated value was the same as normative and even the measured. In luminance based systems, calculation results are often very close to the normative requirement. Bigger differences may arise only by conscious over dimensioning of the system by lighting designer. As a conclusion, SLEEC $_{\mathrm{L}}$ is normally not dependant on normative or calculated luminous parameter or the difference between them is negligible.

As seen from table 2, SLEEC values are very small, namely for the variations $\mathrm{A}$ and $\mathrm{B}$ if power is expressed in $\mathrm{kW}$. For this reason, values in Table 2 are shown in $\mathrm{W} /\left(\mathrm{cd} \cdot \mathrm{m}^{-2} \cdot \mathrm{m}^{2}\right)$. A decision will be needed on how to present SLEEC as practical values.

Table 2: $\quad$ Calculated and measured values of SLEEC $\mathrm{L}_{\mathrm{L}}$

\begin{tabular}{|c|c|c|}
\hline Variation & Calculated & Measured \\
\hline $\mathrm{A}\left(\mathrm{W} /\left(\mathrm{cd} \cdot \mathrm{m}^{-2} \cdot \mathrm{m}^{2}\right)\right.$ & 0,8148 & 0,6560 \\
\hline $\mathrm{B}\left(\mathrm{W} /\left(\mathrm{cd} \cdot \mathrm{m}^{-2} \cdot \mathrm{m}^{2}\right)\right.$ & 0,8148 & 0,6512 \\
\hline $\mathrm{C}\left(\mathrm{kWh} /\left(\mathrm{cd} \cdot \mathrm{m}^{-2} \cdot \mathrm{m}^{2}\right)\right.$ & 3,177 & - \\
\hline $\mathrm{E}\left(\mathrm{kWh} /\left(\mathrm{cd} \cdot \mathrm{m}^{-2} \cdot \mathrm{m}^{2}\right)\right.$ & 2,732 & - \\
\hline
\end{tabular}

Differences between calculated and measured values make $20 \%$. Voltage measured on poles was $215 \mathrm{~V}$ ( $6 \%$ voltage drop). Other influences were not identified though measurements have been performed in each pole.

\section{Conclusions}

Based on proposals and their analyses in this paper we can conclude that:

- Power consumption approach should be preferred against installed power. If no relevant information on lighting switching, control or dimming is available, standard annual operation times can be used.

- Because luminance and illuminance are different design criteria corresponding to different lighting applications, it is not suitable (though it is possible) to unify SLEEC for the two. Therefore, different formulae for $\mathrm{SLEEC}_{\mathrm{L}}$ and $\mathrm{SLEEC}_{\mathrm{E}}$ have to be defined.

- Both normative and calculated luminous parameters coming to the calculation of SLEEC have their benefits but generally usage of normative parameter can be recommended. The other approach does not provide pressure to decrease overall energy demand of lighting systems, that is the main objective of the mandate to elaborate standard.

- Definition or derivation of SLEEC directly from technical parameters of individual components seems to be logical but practical applications may meet with barriers.

- Metering of SLEEC is important to verify the calculated values or it can be a self standing alternative method that can be used e.g. for commissioning of the lighting system. Metering method is proposed in this paper for instantaneous performance, useful for quick verifications. Long term monitoring is a matter of further works on this topic. 


\section{Acknowledgement}

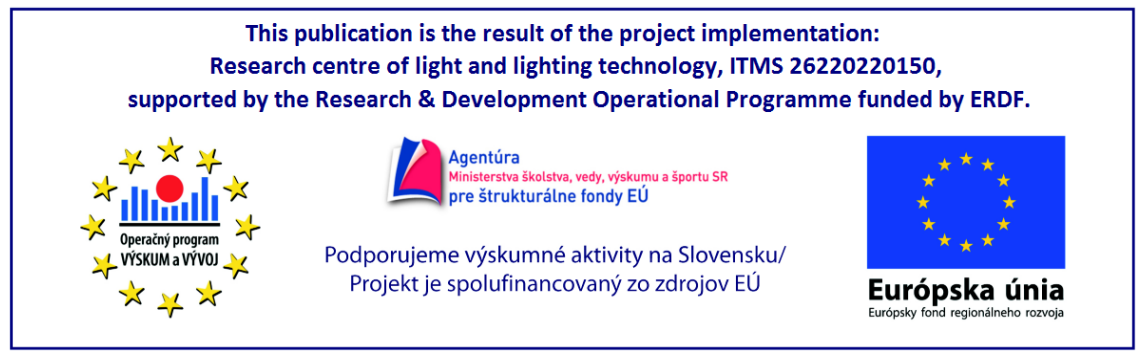

\section{References}

[1] EN 13201: Road lighting (group of standards), 2004

[2] CIE 115: Lighting of Roads for Motor and Pedestrian Traffic, 2010

[3] Sokansky, K. \& Novak, T.: Energy savings in public lighting. Przeglad Elektrotechniczny, 84(8), pp. 72 - 74, 2008

[4] Skoda, J. \& Baxant, P. The reduction in electricity consumption through proper lighting. In proc.:EPE - Electric Power Engineering 2009. Brno University of Technology: Brno, pp. 1-4, 2009

[5] Baxant, P.: Power Consumption Profiles and Potentials of Selected Electrical Appliances as Way to Regulate Electricity Network. Proc. of the 11th International Scientific Conference Electric Power Engineering 2010. Brno University of Technology: Brno, pp. 105 - 110, 2010

[6] Pavelka, T. \& Baxant, P. Comparison of Lighting Regulators in Terms of Energy Savings and Operational Parameters. Proc. of the 11th International Scientific Conference Electric Power Engineering 2010. Brno University of Technology: Brno, pp. 803 - 806, 2010

[7] EN 15193: Energy performance of buildings. Energy requirements for lighting, 2007

[8] Sokansky, K., Novak, T. \& Blaha, Z.: Assessment of parameters of lights for public lighting. Proc. of the 10th International Scientific Conference Electric Power Engineering 2009, VSB TU Ostrava: Ostrava, pp. 194 196, 2009

[9] Güler, Ö. \& Onaygil, S.: A New Criterion for Road Lighting: Average Visibility Level Uniformity. Journal of Light \& Visual Environment, 27(1), pp. 39 - 46, 2003

[10] Onaygil, S., Erkin, E. \& Güler, Ö.: The Effect of Observer Position and Movement on Road Lighting Criteria. Proc. of the 3rd Balkan Conference on Lighting BALKAN LIGHT 2005, Romania, pp. 1 - 7, 2005

[11] Belan, A., Eleschova, Z. \& Smola, M.: Resonance Overvoltages in Electric Power Networks. Proc. of the International Scientific Conference 2005 IEEE St. Petersburg PowerTech. St. Petersburg, p. 465, 2005

[12] Acha, E. \& Madrigal, M.: Power systems harmonics: Computer Modelling and Analysis. John Wiley \& Sons, Ltd.: New York, 2001 
[13] IEEE 519-92: Recommended practice for monitoring electric power quality

[14] Arrillaga, J., Watson, N. R. \& Chen S.: Power system quality assessment. John Wiley \& Sons, Ltd.: Chichester, 2000 